Nenad Blau $\cdot$ Caroline Bernegger $\cdot$ Fritz K. Trefz

\title{
Tetrahydrobiopterin-responsive hyperphenylalaninaemia due to homozygous mutations in the phenylalanine hydroxylase gene
}

Received: 29 May 2002 / Accepted: 3 July 2002 / Published online: 8 August 2002

(C) Springer-Verlag 2002

Sir: Steinfeld et al. [3] reported on three infants with tetrahydrobiopterin $\left(\mathrm{BH}_{4}\right)$-responsive phenylalanine hydroxylase (PAH) deficiency, one of them with a common homozygous Y414C mutation. They questioned the concept of decreased cofactor affinity as a valid explanation for $\mathrm{BH}_{4}$ responsiveness. Recently, we published the first patient with a homozygous L48S mutation presenting with a $\mathrm{BH}_{4}$-responsive $\mathrm{PAH}$ deficiency [1]. While some of mutations in the $P A H$ gene may produce $\mathrm{Km}$ variants which can be activated by $\mathrm{BH}_{4}$ (I65T, V190A, A241C, R261Q, A313T, A373T, E390G, A395P, A403V, P407S, Y414C) the L48S mutation is not located in the DNA coding region for the catalytic domain. Previously described patients were all compound heterozygotes for the above listed mutations and most of these mutations proteins showed $20 \%-30 \%$ residual activity when recombinantly expressed in eukaryotic cell systems[1]. Thus, mechanisms different from the low cofactor affinity may be responsible for the phenotype in patient with the L48S mutation.

The recent finding that $\mathrm{BH}_{4}(200 \mathrm{mg} / \mathrm{kg}$ ip) increases the PAH mRNA, enzyme activity and protein levels by $50 \%$ in a $h p h-1$ mouse suggested the $\mathrm{BH}_{4}$ can regulate $P A H$ gene expression [2]. We proposed that in patient with the L48S mutation, and this may also be true for some other homozygous mutations, $\mathrm{BH}_{4}$ increases enzyme activity by inducing the gene expression. However, one cannot exclude that in some patients the $\mathrm{BH}_{4}$ responsiveness is due to both a $\mathrm{Km}$ variant and increased $P A H$ gene expression.

These data stress the importance of the $\mathrm{BH}_{4}$ loading test and of $\mathrm{BH}_{4}$ as a potential practical alternative in the treatment of mild hyperphenylalaninaemia. Our preliminary data indicate that $\mathrm{BH}_{4}$-responsive $\mathrm{PAH}$ deficiency is more common than initially assumed. Around $70 \%$ of patients with initial plasma phenylalanine levels below $800 \mu \mathrm{mol} / 1$ respond to the loading test with $20 \mathrm{mg} \mathrm{BH} / \mathrm{kg}$ body weight (C. Bernegger and N. Blau, unpublished observation).

\section{References}

1. Blau N, Trefz FK (2002) Tetrahydrobiopterin-responsive phenylalanine hydroxylase deficiency: possible regulation of gene expression in a patient with the homozygous L48S mutation. Mol Genet Metab 75: 186-187

2. Hyland K, Munk-Martin TL (2001) Tetrahydrobiopterin regulates tyrosine hydroxylase and phenylalanine hydroxylase gene expression in dominatly inherited GTP cyclohydrolase deficiency. J Inherit Metab Dis 24: 30

3. Steinfeld R, Kohlschütter A, Zschocke J, Lindner M, Ullrich K, Lukacs Z (2002) Tetrahydrobiopterin monotherapy for phenylketonuria patients with common mild mutations. Eur J Pediatr 161: 403-405
N. Blau $(\bowtie) \cdot$ C. Bernegger

Division of Clinical Chemistry and Biochemistry,

University Children's Hospital, Steinwiesstrasse 75,

8032 Zurich, Switzerland

E-mail: Nenad.Blau@kispi.unizh.ch

Tel.: +41-1-2667544

Fax: + 41-1-2667169

F.K. Trefz

Children's Hospital Reutlingen, School of Medicine,

University of Tübingen, Reutlingen, Germany 